\title{
Diversidade genética de porta-enxertos cítricos baseada em marcadores moleculares RAPD ${ }^{1}$
}

\author{
Genetic diversity of citrus rootstocks based on RAPD marker analysis
}

\author{
Gilmar Schäfer ${ }^{2}$ Marinês Bastianel ${ }^{3}$ Ana Lúcia Cunha Dornelles ${ }^{4}$
}

\section{RESUMO}

Este trabalho teve como objetivo caracterizar a diversidade genética, através do marcador molecular RAPD, dos porta-enxertos da Coleção de Citros da Estação Experimental Agronômica da Universidade Federal do Rio Grande do Sul (EEA/UFRGS) e acessos de porta-enxertos cítricos coletados em viveiristas da Região do Vale do Rio Caí do estado do Rio Grande do Sul. Para tanto, coletaram-se folhas de nove porta-enxertos cítricos da EEA/UFRGS e de dez acessos de trifoliata (Poncirus trifoliata) de viveiristas. Com o uso de nove seqüências inicializadoras, foi possível separar os porta-enxertos cítricos em dois grupos principais, um formado pelo limoeiro 'Cravo' e outro pelo trifoliata e seus híbridos, apresentando alta dissimilaridade genética entre os grupos. Marcadores moleculares RAPD foram eficientes para caracterizar variedades de porta-enxertos de citros $e$ para separar o porta-enxerto $\boldsymbol{P}$. trifoliata de seus híbridos podendo serem utilizados para caracterização de plantas matrizes, análise de variabilidade genética entre genitores em programas de melhoramento genético de porta-enxertos e para identificar a origem sexual ou nucelar de mudas de trifoliata em viveiros comerciais.

Palavras-chave: citrus, Poncirus trifoliata, Citrus limonia

\section{ABSTRACT}

This research intended to characterize the genetic diversity of citrus rootstocks from the Experimental Agronomic Station of the Rio Grande do Sul Federal University (EEA/ UFRGS) and rootstocks collected in nurseries of the Cai River Valley - Rio Grande do Sul - Brazil. The method used was the Random Amplification of Polymorphic DNA (RAPD) markers. Leaves of nine citrus rootstocks from EEA/UFRGS and ten accesses of trifoliate orange (Poncirus trifoliata) from different nurseries were collected. With the use of nine random primers it was possible to separate the rootstocks in two main groups: one formed by 'Rangpur' lime (Citrus limonia) and the other by trifoliate orange and its hybrids of low genetic similarity. $R A P D$ molecular marker was very efficient for the citrus rootstock characterization and for the trifoliate orange separation from its hybrids. The technique might be used to characterize cultivars, analysis of genetic variability among progenitors in improvement breeding programs of rootstock, and identify zygotic seedlings of trifoliate orange in commercial nurseries.

Key words: citrus, Poncirus trifoliata, Citrus limonia.

\section{INTRODUÇÃO}

A citricultura brasileira, dentro da economia nacional e mundial, apresenta um papel de destaque, tanto pela maior produção mundial, como pela exportação de suco. No Rio Grande do Sul, a produção citrícola apresenta um papel fundamental na fixação do homem no campo, pois localiza-se principalmente nas margens dos rios Caí e Taquari, cuja região é composta, em grande parte, por pequenas propriedades rurais (DORNELLES, 1991), produzindo frutos principalmente para o consumo de mesa.

Devido ao seu caráter perene, a muda cítrica é o fator mais importante na formação de um pomar. Os principais atributos de uma muda de boa qualidade podem ser atribuídos à origem do enxerto e do portaenxerto (plantas matrizes) e a qualidade do sistema radicular (LIMA, 1986). O uso de porta-enxertos, por afetar mais de 20 características hortícolas e patológicas

${ }^{1}$ Parte da Dissertação de Mestrado apresentada pelo primeiro autor ao curso de Fitotecnia da Universidade Federal do Rio Grande do Sul (UFRGS). Trabalho realizado com apoio financeiro da Coordenação de Aperfeiçoamento de Pessoal de Nível Superior (CAPES) e Fundação de Amparo à Pesquisa do Rio Grande do Sul (FAPERGS).

${ }^{2}$ Engenheiro Agrônomo, MSc, aluno do Programa de Pós-graduação em Fitotecnia da Faculdade de Agronomia da UFRGS. Email: gilmarschafer@hotmail.com

${ }^{3}$ Engenheiro Agrônomo, MSc, Doutorando em Genética e Biologia Molecular da Universidade Estadual de Campinas (UNICAMP) E-mail: mbastianel@yahoo.com

${ }^{4}$ Engenheiro Agrônomo, Doutor, Professor Adjunto da Faculdade de Agronomia da UFRGS, Departamento de Horticultura e Silvicultura, Av. Bento Gonçalves 7712, 91540-000, Porto Alegre, RS.. E-mail: alcunha@vortex.ufrgs.br 
da cultivar copa e frutos, é considerado essencial na citricultura (SCHÄFER et al., 2001). Estima-se que $90 \%$ das mudas produzidas no Rio Grande do Sul estão enxertadas sobre Poncirus trifoliata (MORAES et al., 1998; SCHÄFER \& DORNELLES, 2000). Autilização de um único porta-enxerto torna a citricultura vulnerável ao surgimento de moléstias, podendo ocasionar danos econômicos severos, como foi o caso da tristeza dos citros, do declínio (BERETTA et al., 1989) ou, mais recentemente, da morte súbita dos citros (FUNDECITRUS, 2002).

As sementes de citros geralmente são poliembriônicas, isto é, possuem dois ou mais embriões em uma mesma semente. Normalmente, um embrião é zigótico, resultante da fecundação, e os demais são produzidos assexualmente por divisões mitóticas de células somáticas do nucelo e, por isso, são chamados de embriões nucelares (KOLLER, 1994; FROST \& SOOST, 1968). Na germinação das sementes, geralmente os embriões nucelares nascem com mais vigor, dominando os embriões resultantes da fecundação, cujas mudas raramente ou pouco se desenvolvem (KOLLER, 1994). A seleção das plantas pelo viveirista é feita pelo seu vigor, descartando aquelas com menor desenvolvimento vegetativo, que são possivelmente resultantes da germinação do embrião zigótico. Isso proporciona um elevado índice de mudas com características idênticas às da planta matriz, justificando a obtenção de porta-enxertos de citros por meio de sementes (KOLLER, 1994). Entretanto, CRISTOFANI \& MACHADO (1998) detectaram por meio da caracterização molecular de porta-enxertos de limoeiro 'Cravo' a ocorrência de germinação de embrião zigóticos e sua posterior seleção. Além desse trabalho, SOARES FILHO et al. (1991) sugeriram a existência de variabilidade genética em populações do porta-enxertos limoeiro 'Cravo'. Estas considerações associadas ao fato dos viveiristas costumeiramente formarem suas plantas matrizes a partir de mudas propagadas por sementes, aumentam a probabilidade de se detectar variabilidade genética entre estes.

A análise genética de indivíduos tem sido revolucionada nestes últimos anos, através do desenvolvimento da técnica de amplificação de seqüências de DNA, que permite a comparação direta dos alelos, através da composição em nucleotídeos da sequiência. Esta metodologia, denominada de PCR (Reação de polimerase em cadeia), permite comparar os organismos ao nível molecular, sem influência do ambiente ou idade do tecido (FERREIRA \& GRATTAPAGLIA, 1995). Variações da PCR, tais como RAPD (Amplificação polimórfica de DNA ao acaso) têm sido amplamente utilizadas para estudos genéticos em citros (MORELL et al., 1995; MACHADO et al., 1996; CRISTOFANI, 1997; COLETTA FILHO et al., 1998, BASTIANEL et al, 1998).

Este trabalho teve como objetivo caracterizar a diversidade genética, através do marcador molecular RAPD, de porta-enxertos existentes na coleção de citros da Estação Experimental Agronômica da Universidade Federal do Rio Grande do Sul e acessos de porta-enxertos coletados em viveiristas da região do Vale do Rio Caí, principal região produtora de mudas cítricas do Estado do Rio Grande do Sul.

\section{MATERIAL E MÉTODOS}

O material vegetal foi coletado de plantas presentes na coleção de citros da Estação Experimental Agronômica da Universidade Federal do Rio Grande do Sul (EEA/UFRGS), localizada no município de Eldorado do Sul e de bancos de sementes de viveiristas da região do Vale do Rio Caí, Rio Grande do Sul (Tabela 1).

Foram coletadas, aleatoriamente, 10 a 20 folhas jovens e sadias de uma planta de cada acesso. A extração do DNA genômico foi realizada segundo metodologia descrita por MURRAY \& THOMPSON (1980), com algumas modificações sugeridas por MACHADO et al. (1996). A quantificação e qualificação do DNA genômico foi efetuada segundo metodologia descrita por SAMBROOK et al. (1989).

As reações de amplificação foram preparadas em um volume de 12,3 $\mu$ l contendo: 2 unidades da enzima Taq polimerase (Cenbiot/RS), $1 \mu \mathrm{l}$ de dNTPs - 200mM de cada dATP, dTTP, dCTPe dGTP(Gibco), 1,3 $\mu 1$ de tampão 10X (100mM Tris-HCl pH 8,3, 500mM KCl, 2,0mM de $\mathrm{MgCl}_{2}$ e $0,01 \%$ de gelatina), $3 \mu \mathrm{l}(15 \mathrm{ng}$ ) de seqüências inicializadoras de 8 e 10 nucleotídeos (Tabela 2), $2 \mu \mathrm{lda}$ solução de DNA (10ng) e o restante de $\mathrm{H}_{2} \mathrm{O}$ mili-Q autoclavada. Para evitar a evaporação durante o ciclo PCR, foram adicionados $10 \mu 1$ de óleo mineral. A amplificação foi conduzida em um termociclador Eppendorf ${ }^{\circledR}$, programado para: 36 ciclos de um minuto a $92^{\circ} \mathrm{C}$, um minuto a $36^{\circ} \mathrm{Ce}$ dois minutos a $72^{\circ} \mathrm{C}$, acrescidos de 10 minutos a $72^{\circ} \mathrm{C}$ ao final do último ciclo. As sequiências inicializadoras foram selecionadas, segundo resultados obtidos por diversos autores em citros, as quais apresentavam alto grau de polimorfismo (Tabela 2).

Os padrões de amplificação foram resolvidos em gel de agarose $1,4 \%$, preparado com tampão TAE $1 \mathrm{X}$ (0,04M tris acetato e 1mM de EDTA) e corados com brometo de etídeo. O peso molecular das bandas obtidas nas análises foi estimada com o uso do software GEL (SCHAFFER \& SEDEROFF, 1989). A análise dos dados moleculares, entre os 
Tabela 1 - Relação e procedência dos porta-enxertos cítricos utilizados na análise de RAPD. Porto Alegre, 1999.

\begin{tabular}{|c|c|c|c|}
\hline Nome comum & Sigla & Nome científico & Procedência \\
\hline Limoeiro 'Cravo' & ‘Cravo’ & Citrus limonia Osbeck & EEA/UFRGS \\
\hline Trifoliata 'Limeira' & 'Limeira' & Poncirus trifoliata (L.) Raf. & EEA/UFRGS \\
\hline Trifoliata & Trif. & Poncirus trifoliata (L.) Raf. & EEA/UFRGS \\
\hline Trifoliata 'Flying Dragon' & Dragon & Poncirus trifoliata (L.) Raf. & EEA/UFRGS \\
\hline Citrumeleiro 'Swingle' & 'Swingle' & P. trifoliata (L.) Raf. vs Citrus paradisi Macf & EEA/UFRGS \\
\hline Citrange ' $41^{, 1}$ & C. ' 41 ' & P. trifoliata (L.) Raf. vs C. sinensis Osbeck & EEA/UFRGS \\
\hline Citrange ' 13 ' & C. ' 13 ' & P. trifoliata (L.) Raf. vs C. sinensis Osbeck & EEA/UFRGS \\
\hline Citrange $37^{1}$ & C. '37' & P. trifoliata (L.) Raf. vs $\boldsymbol{C}$. sinensis Osbeck & EEA/UFRGS \\
\hline Citrange 'Troyer' & 'Troyer' & P. trifoliata (L.) Raf. vs C. sinensis Osbeck & EEA/UFRGS \\
\hline Trifoliata viveiro 1 & Trif. 1 & Poncirus trifoliata (L.) Raf & São Sebastião do Caí \\
\hline Trifoliata viveiro 2 & Trif. 2 & Poncirus trifoliata (L.) Raf & Pareci Novo \\
\hline Trifoliata viveiro 3 & Trif. 3 & Poncirus trifoliata (L.) Raf & Pareci Novo \\
\hline Trifoliata viveiro 4 & Trif. 4 & Poncirus trifoliata (L.) Raf & Pareci Novo \\
\hline Trifoliata viveiro 5 & Trif. 5 & Poncirus trifoliata (L.) Raf & Pareci Novo \\
\hline Trifoliata viveiro 6 & Trif. 6 & Poncirus trifoliata (L.) Raf & Taquari \\
\hline Trifoliata viveiro 7 & Trif. 7 & Poncirus trifoliata (L.) Raf & Taquari \\
\hline Trifoliata viveiro 8 & Trif. 8 & Poncirus trifoliata (L.) Raf & Montenegro \\
\hline Trifoliata viveiro 9 & Trif. 9 & Poncirus trifoliata (L.) Raf & Montenegro \\
\hline Trifoliata viveiro 10 & Trif. 10 & Poncirus trifoliata (L.) Raf & São Sebastião do Caí \\
\hline
\end{tabular}

${ }^{1}$ Porta-enxertos cítricos desenvolvidos pelo Centro de Pesquisa de Fruticultura de Taquari - RS da FEPAGRO.

acessos de porta-enxertos cítricos, foi realizada tendo como base uma matriz considerando os dados binários, onde o valor 1 (um) foi atribuído para a presença do fragmento (banda) e o valor 0 (zero) para a ausência. Os dados foram analisados utilizando-se o sistema de taxonomia numérica e multivariada através do programa NTSYS - Versão 1.7 (ROHLF, 1992), onde a matriz de similaridade foi gerada pelo coeficiente 'SM' (Simple Matching). O dendrograma foi construído pelo método UPGMA ("Unweighted Pair Group Method with Aritmetic Average").

\section{RESULTADOS E DISCUSSÃO}

A análise genética dos porta-enxertos cítricos, com nove oligonucleotídeos inicializadores, resultaram em 67 fragmentos amplificados com um total de 57 fragmentos polimórficos (Tabela 2). Desses, foram encontrados marcadores específicos para o limoeiro 'Cravo' (P130_1700pb; OPH15_1556pb; OPM05_1184pb e 805pb; OPA05_791pb; OPA09_690pb e 496pb; OPA04_2079pb e1319pb e OPI11_2492, 1780, 1016, 671, 488pb), Citrumeleiro 'Swingle' (OPA09_945pb e OPN14_815pb), Citrange '41' (OPN14_1479pb) e Poncirus trifoliata 'Flying Dragon' (OPH15_986pb).

O baixo grau de similaridade $(34 \%)$ encontrado entre o acesso de limoeiro 'Cravo' e os demais porta-enxertos (Figura 1) pode ser justificado pelo fato dos acessos pertencerem a dois gêneros diferentes (Citrus e Poncirus), os quais pertencem à família Rutaceae e subfamília Aurantioideae (ORTIZ

Tabela 2 - Relação das seqüências inicializadoras de RAPD utilizadas na análise genética de 19 acessos de porta-enxertos cítricos com suas referências bibliográficas e o número de fragmentos amplificados e polimórficos, Porto Alegre, 1999.

\begin{tabular}{|c|c|c|c|c|}
\hline \multirow{2}{*}{ Seqüência inicializadora } & \multirow{2}{*}{ Seqüência } & \multirow{2}{*}{ Referência } & \multicolumn{2}{|c|}{ Número de fragmentos } \\
\hline & & & Amplificados & Polimórficos \\
\hline $\mathrm{P} 130$ & $5^{\prime} \quad$ CGCGGCCA $3^{\prime}$ & Targon et al. (1998) & 5 & 4 \\
\hline OPH15 & $5^{\prime}$ AATGGCGCAG 3' & Bastianel (1998) & 6 & 5 \\
\hline OPM05 & 5' GGGAACGTGT 3' & Cristofani (1997) & 6 & 5 \\
\hline OPA05 & 5'AGGGGTCTTG 3' & Cai et al. (1994) & 5 & 4 \\
\hline OPA09 & $5^{\prime}$ GGGTAACGCC $3^{\prime}$ & Cai et al. (1994) & 9 & 9 \\
\hline OPN14 & $5^{\prime}$ TCGTGCGGGT 3' & Cristofani (1997) & 11 & 10 \\
\hline OPT08 & $5^{\prime}$ AACGGCGACA $3^{\prime}$ & Cai et al. (1994) & 5 & 1 \\
\hline OPA04 & 5'AATCGGGCTG 3' & Cai et al. (1994) & 8 & 7 \\
\hline OPI11 & 5' GGAAGTCGCC 3' & Bastianel (1999) & 12 & 12 \\
\hline Total & & & 67 & 57 \\
\hline
\end{tabular}




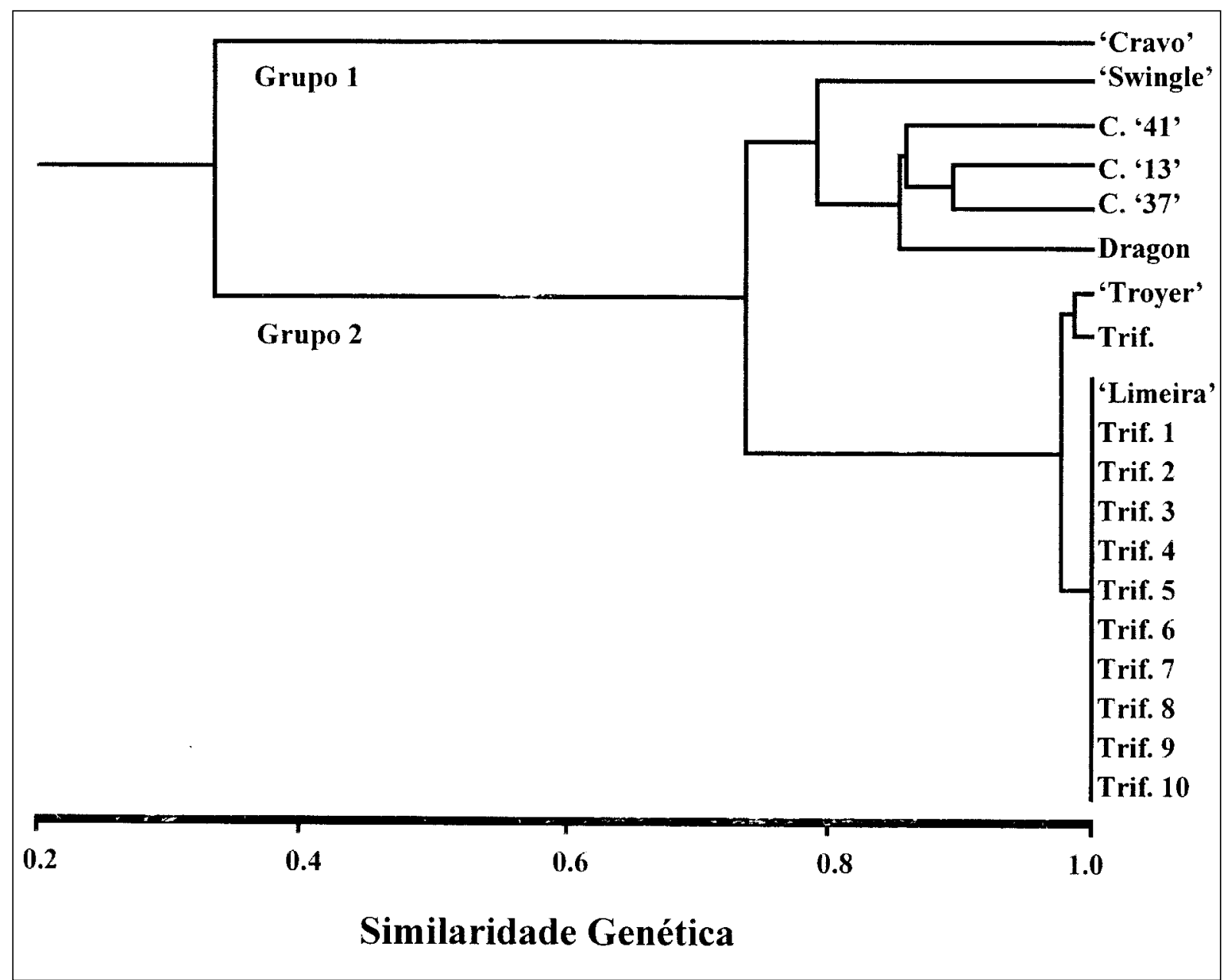

Figura 1 - Dendrograma entre os acessos de porta-enxertos cítricos indicando as relações genéticas e a porcentagem de similaridade obtida a partir do coeficiente 'SM', Porto Alegre, 1999. Siglas dos porta-enxertos conforme a Tabela 1.

MARCIDE, 1985), que caracterizam o termo genérico empregado aos citros. Características morfológicas também realçam diferenças entre Citrus limonia e Poncirus trifoliata e seus híbridos com Citrus sinensis (citranges) e Citrus paradisi (citrumelos), como: folhas trifolioladas e caducifólias, formato do fruto, presença abundante de espinhos, entre outros (KOLLER, 1994). Em trabalho de caracterização de clones de limoeiro 'Cravo' e outros limoeiros (C. jambhiri, $\boldsymbol{C}$. volkameriana, $\boldsymbol{C}$. pennivesiculata e híbridos), com marcadores RAPDs, encontrou-se um nível de similaridade de $68 \%$ entre $\boldsymbol{C}$. limonia e os demais (SILVA, 1996).

Outro grupo foi constituído por Poncirus trifoliata (L.) Raf. e seus híbridos (Citrumeleiro 'Swingle', Citranges '41', '13', '37' e 'Troyer') apresentando graus de similaridade variando de 66 a $100 \%$ (Figura 1). Neste grupo, destaca-se a formação de dois subgrupos, aos quais a análise de RAPDs apresentou similaridade máxima entre os acessos de trifoliata coletados nos viveiristas e o Trifoliata 'Limeira', estes apresentando similaridade de $98 \%$ com o Trifoliata EEA e Citrange 'Troyer' e similaridades menores, com o segundo subgrupo, formado pelos acessos de híbridos de Trifoliata e o Trifoliata 'Flying Dragon'. A técnica RAPD detectou variabilidade na maioria das plantas híbridas, o que já havia sido apontado por BASTIANEL et al. (1998), BASTIANEL (1999) e SILVA (1996) que classificaram híbridos de 'King' com 'Montenegrina', híbridos de 'Lee' e clones de limoeiro 'Cravo', respectivamente. Entretanto, nesse estudo, os marcadores RAPDs não foram eficientes em separar o Citrange 'Troyer' do seu genitor masculino (P. trifoliata) e acessos de Trifoliata dos viveiristas (Figura 1).

Uma baixa dissimilaridade genética $(<3 \%)$ foi encontrada entre o acesso de $\boldsymbol{P}$. Trifoliata oriundo 
da EEA-UFRGS e os demais acessos desta espécie coletados em outros locais, os quais apresentaram similaridade máxima entre si (Figura 1). Essa planta, por ter sido originada de uma semente do acesso $\boldsymbol{P}$. trifoliata 'Taquari' (KOLLER, 2000 - Informe verbal), possivelmente seja oriunda da germinação do embrião zigótico e, portanto, não é um clone e sim uma planta proveniente de reprodução sexual (autopolinização ou polinização cruzada). Esse resultado evidencia a probabilidade de híbridos naturais de $\boldsymbol{P}$. Trifoliata estarem sendo utilizados como plantas matrizes de sementes em viveiros comerciais. Por outro lado, existem evidências de que todas as plantas matrizes utilizadas pelos viveiristas e analisadas neste trabalho, sejam oriundas de sementes obtidas desta mesma planta - P. Trifoliata 'Taquari' (DORNELLES, 1999 Informe verbal), e desta forma, essas plantas teriam sido obtidas por reprodução assexual, via embrionia nucelar e, portanto, apresentariam a mesma constituição genética evidenciada por este trabalho.

Entretanto, a similaridade máxima encontrada entre os acessos de P. trifoliata proveniente de viveiristas, pode ser devida à limitação do marcador molecular RAPD, que, enquanto marcador de natureza dominante, não é capaz de discriminar adequadamente a ocorrência de heteromorfismos intralocos (SILVA, 1996; TINGEY \& DEL TUFO, 1993). A discriminação entre materiais muito aparentados com o uso de marcadores RAPD pode ser alcançada quando se aumenta o número de bandas polimórficas, por meio do uso de um maior número de oligonucleotídeos inicializadores (WELSH et al., 1991; JAIN et al., 1994; FERREIRA \& GRATTAPLAGIA, 1995) ou do uso de outros marcadores moleculares não dominantes, como microssatélites e RFLP (BASTIANEL, 1999; THOMAS et al., 1998, FERREIRA \& GRATTAPLAGIA, 1995).

A característica de nanismo do porta-enxerto

$\boldsymbol{P}$. trifoliata 'Flying Dragon' originou-se a partir de uma mutação do Trifoliata com genótipo de estatura normal, não sofrendo recombinação sexual desde este evento (CHENG \& ROOSE, 1995), o que sugere um elevado grau de parentesco entre esses dois acessos. No entanto, nesse estudo, o acesso de $\boldsymbol{P}$. trifoliata 'Flying Dragon' revelou-se com um grau de polimorfismo elevado em comparação ao P. trifoliata (L.) Raf. (Figura 1), sugerindo uma variabilidade maior do que a esperada, por serem indivíduos tão aparentados. Este resultado evidencia a presença de variabilidade genética dentro do gênero Poncirus que pode ser explorada em programas de melhoramento genético, com vistas a obtenção de novas variedades comerciais e, desta forma, diversificar a utilização de porta-enxertos na citricultura gaúcha.

\section{CONCLUSÃO}

Marcadores moleculares RAPD foram eficientes para caracterizar variedades de portaenxertos de citros e para separar o porta-enxerto $\boldsymbol{P}$. trifoliata de seus híbridos podendo serem utilizados para caracterização de plantas matrizes, análise de variabilidade genética entre genitores em programas de melhoramento genético de porta-enxertos e para identificar a origem sexual ou nucelar de mudas de trifoliata em viveiros comerciais.

\section{COMUNICAÇÃOPESSOAL}

DORNELLES, C. M. M. Fundação Estadual de Pesquisa Agropecuária da Secretaria da Ciência e Tecnologia do Estado do Rio Grande do Sul, Caixa Postal 12, CEP 95860000 - Taquari - RS. Introdução e difusão do porta-enxerto Poncirus trifoliata no Rio Grande do Sul. Taquari: 1999. Comunicação pessoal. E-mail: fruticultura@fepagro.rs.gov.br KOLLER, O. C. Faculdade de Agronomia da UFRGS, Departamento de Horticultura e Silvicultura, Av. Bento Gonçalves 7712, Agronomia, CEP 91540-000 - Porto Alegre - RS. Procedência dos acessos de Poncirus trifoliata da coleção de citros da Estação Experimental Agronômica da Universidade Federal do Rio Grande do Sul. Porto Alegre: 2000. Comunicação pessoal. E-mail: ockoller@orion.ufrgs.br.

\section{REFERÊNCIAS BIBLIOGRÁFICAS}

BASTIANEL, M. Análise de uma população segregante de tangerineira 'Lee' [Citrus reticulata $\times$ (C. tangerina $x$ $C$. paradisi)] através de RAPD e marcadores morfológicos. 1999. 91f. Dissertação (Mestrado em Fitotecnia)-Programa de Pós-graduação em Fitotecnia, Universidade Federal do Rio Grande do Sul.

BASTIANEL, M. et al. Identification of zygotic and nucellar tangerine seedlings (citrus spp.) using RAPD. Genetics and Molecular Biology, Ribeirão Preto, v.21, n.1, p.123-127, 1998.

BERETTA, M.J.G. et al. Aplicação dos testes diagnósticos para declínio em plantas cítricas submetidas à transmissão por enxertia de aproximação de raízes. Laranja, Corderópolis, v.10, n.2, p.335-346, 1989.

CAI, Q.; GUY, C.L.; MOORE, G.A. Extension of the linkage map in Citrus using random amplified polymorphic DNA (RAPD) markers and RFLP mapping of cold-acclimationresponsive loci. Theoretical and Applied Genetics, Berlin, n.89, p.606-614, 1994.

CHENG, F.S.; ROOSE, M.L. Origin and inheritance of dwarfing by the Citrus rootstock Poncirus trifoliata 'Flying Dragon'. Journal of the American Society for Horticultural Science, Alexandria, v.120, n.2, p.286291, 1995.

COLETTA FILHO, H.D. et al. Analysis of the genetic among mandarins (Citrus spp.) using RAPD markers. Euphytica, Berlin, n.102, p.133-139, 1998. 
CRISTOFAnI, M. Mapas de ligação de Citrus sunki Hort. ex. Tan. E Poncirus trifoliata (L.) Raf. Cv. Rubidoux e localização do gene de resistência ao vírus da tristeza. 1997. 152f. Tese (Doutorado em Agronomia Genética e Melhoramento de Plantas) Escola Superior de Agricultura 'Luiz de Queiroz', Universidade de São Paulo.

CRISTOFANI, M.; MACHADO, M.A. Utilização de marcadores moleculares na identificação de plântulas zigóticas e nucelares em sementeira de limão 'Cravo'. Laranja, Corderópolis, v.19, n.1, p.159-166, 1998.

DORNELLES, C.M.M. Citricultura do Rio Grande do Sul. In: RODRIGUES, O. et al. Citricultura brasileira. Campinas: Fundação Cargill, 1991. V.1, p.38-41.

FERREIRA, M.E.; GRATTAPAGLIA, D. Introdução ao uso de marcadores RAPD e RFLP em análise genética. Brasília : EMBRAPA, 1995. 220p.

FROST, H.B.; SOOST, R.K. Seed reproduction: development of gametes and embryos. In: REUTHER, W.H.J. (Ed). The citrus Industry. Berkeley : University of California, 1968. V.2, p.290-324.

FUNDECITRUS. Revista do Fundecitrus, Araraquara, SP. n.113, p.10-13, nov/dez, 2002.

JAIN, A. et al. Potential use of random amplified polymorphic DNA (RAPD) technique to study the genetic diversity in Indian mustard (Brassica juncea) and its relationship to heterosis. Theoretical Applied Genetics, Berlin. n.88, p.116-122, 1994.

KOLLER, O.C. Citricultura: laranja, limão e tangerina, Porto Alegre : Rigel, 1994. 446p.

LIMA, J.E.O. de. Novas técnicas de produção de mudas cítricas. Laranja, Corderópolis, v.7, n.2, p.463-468, 1986.

MACHADO, M.A. et al. Genetic relationship of Mediterranean mandarins (Citrus deliciosa Tenore) using RAPD markers. Euphytica, Berlin, n.92, p.321-326, 1996.

MORAES, L.A.H. et al. Cadeia produtiva da laranja no Rio Grande do Sul. Porto Alegre : Fundação Estadual de Pesquisa Agropecuária/SCT, 1998. 49p. (Boletim Técnico FEPAGRO, 5).

MORELL, M.K. et al. DNA profiling techniques for plant variety identification. Australian Journal of Experimental Agriculture, Merbein, n.35, p. 807-819, 1995 .
MURRAY, M.G.; THOMPSOM, W.F. Rapid isolation of high molecular weight plant DNA. Nucleic Acids Research, Cary, n.8, p.4321-4325, 1980.

ORTIZ MARCIDE, J.M. Nomenclatura botânica de los cítricos. Levante Agrícola, Valência, n.71, p.259-260, 1985.

ROHLF, F.J. NTSYS - PC numerical taxonomy and multivariate analysis system. Version 1.7. New York: State University of New York, 1992.

SAMBROOK, J.; FRITSCH, E. F.; MANIATIS, T. Molecular cloning: a laboratory manual. New York : Cold Spring Harbor Laboratory, 1989. V.3, não paginado.

SCHÄFER, G.; BASTIANEL, M.; DORNELLES, A.L.C. Porta-enxertos utilizados na citricultura. Ciência Rural, Santa Maria, v.31, n.4, p.723-733, 2001.

SCHÄFER, G.; DORNELLES, A.L.C. Produção de mudas cítricas no Rio Grande do Sul - Diagnóstico da região produtora. Ciência Rural, Santa Maria, v.30, n.4, p.587-592, 2000.

SCHAFFER, H.E.; SEDEROFF, R.R. Improved estimation of DNA fragment lenghts from agarose gels. Annal Biochem. n.115. p.113-122, 1989.

SILVA, B.A. O uso de marcadores moleculares e descritores morfológicos na caracterização de clones de limão cravo (Citrus limonia Osb.). 1996. 83f. Tese (Doutorado em Ciências Biológicas-Genética) - Programa de Pós-graduação em Ciências Biológicas, Universidade Estadual Paulista 'Júlio de Mesquita Filho'.

SOARES FILHO, W.S. et al. Variabilidade genética em "limão 'Cravo"”. Revista Brasileira de Fruticultura, Cruz das Almas, v.13, n.3, p.267-272, 1991.

TARGON, M.L.P.N.; MACHADO, M.A.; POMPEU Jr. J. Marcadores 'RAPD' para identificação de plântulas de citrange e citrumelo. Laranja, Corderópolis, v.19, n.2, p.375-381, 1998.

THOMAS, M.R. et al. Sequence-Tagged site markers in grapevine and citrus. Journal of the Japanese Society for Horticultural Science, Tokyo, v.67, n.6, p.1189$1192,1998$.

TINGEY, S.V.; DEL TUFO, J.P. Genetic analysis with Random Amplified polynorphic DNA markers. Plant Physiology, Denville, n.101, p.349-352, 1993.

WELSH, J. et al. Parentage determination in maize hybrids using the arbitrarily primed polymerase chain reaction (APPCR). Theoretical and Applied Genetics, Berlin, n.82, p.473-476, 1991. 